\title{
The Bridging Problem Study of College English Teaching and Bilingual Teaching
}

\author{
Weiwei Wang ${ }^{1, a}$ and Lan $\mathrm{Wu}^{2, \mathrm{~b}}$ \\ ${ }^{1,2}$ Air Force Engineering University, Xi'an, China \\ avivian79252005@163.com, b2247255224@qq.com
}

\begin{abstract}
Keywords: College English teaching; Bilingual teaching; The problem; Research
\end{abstract}
\begin{abstract}
The bilingual teaching in colleges and universities in our country have been pushing for years, but in college English teaching and bilingual teaching exists between the certain problem, although say now after a period of improvement, our country university of college English teaching and bilingual teaching cohesion between have made certain progress, but there still exist many deficiencies. To improve the teaching effect of bilingual teaching, the first to start from the college English teaching reform, try teaching mode based on subject content, and pay attention to cultivate the students' English thinking ability. The mode of bilingual teaching, appropriate USES by bilingual teaching to make students in learning professional knowledge at the same time, synchronous improve language using ability, eventually transition to simple are conducted in a foreign language teaching. To improve the effectiveness of bilingual teaching, we should improve the English expression ability of bilingual teachers in specialized courses, and guarantee the teaching of bilingual teaching.
\end{abstract}

\section{Introduction}

College English is general English in addition to basic English. The current college English education in our country mainly adopts computer classroom and multimedia classroom teaching mode, the main teaching goal is to improve students' English comprehensive application ability and autonomous learning ability, don't need to pursue the integrity of the teaching, but pay attention to the English language and practical application ability.

\section{The Goal of Bilingual Education}

The goal of bilingual education can be identified in the following three aspects: (1) the target of professional knowledge. To direct students to the advanced scientific and technical knowledge of foreign countries. At the same time, the original English professional teaching materials, the writing thoughts, system structure, content and choose from multiple aspects, such as configuration, exercises has difference with our materials. This makes it possible for students to learn from another perspective and to think about their courses in order to enhance their understanding. (2) the goal of improving the use of English. Bilingual teaching can improve students' ability of English language. In Chinese, English learning professional courses, in the process of training, the students' English level, professional and vocational ability to use English. (3) cultural goals. Bilingual teaching is not only refers to "in a foreign language class", was more of an emphasis in a foreign language in classroom learning communication between teachers and students and interaction, more emphasis on "dual culture". The culture of the bilingual teaching goal is to enable students to use two languages native language and foreign language thinking, can according to the communication between two languages object and the need to switch language environment, so that they have the ability to cross-cultural communication, thus in the field, in the great success in his career. Any language, political system, code of conduct is established in a certain cultural soil. There are differences in people's thinking is also due to the difference of culture, such as western culture typical way of thinking is linear, causal thinking, is also causes the result; Chinese thinking is 
circular. Cultural differences can lead to the selection of teaching ideas, chapters, content and different teaching styles.

\section{The Problems and Causes of Current Bilingual Teaching}

It is Difficult for students to Adapt to the Actual needs of Bilingual Teaching. Although the student's thought step by step forward, vision gradually develops, many students also can fundamentally understand the importance of bilingual teaching activities, but in essence is not willing to accept the bilingual teaching activities. Is mainly due to the students affected by the traditional teaching, many students' English level is still in a low standard, particularly in terms of listening, speaking, reading and writing can't adapt to the actual needs of the bilingual teaching, and therefore in the teaching, students is limited by its own level, lead to the whole teaching effect of bilingual teaching is not very ideal, according to the survey can be learned, to be able to understand $90 \%$ of current bilingual teaching the students of English, less than 8\%, and can understand English teaching content is $35 \%$, but $66 \%$ people, look from the digital gap between becomes more and more obvious. Based on this, the analysis can be realized that the difficulty of bilingual teaching is difficult to achieve the desired effect, and the reason is to seek from the listening and reading. First, listen to, the traditional college English teaching process, teachers in addition to the special English nouns, are used to use Chinese expression, so students also get the Chinese in learning English learning effect, so can't meet the requirements for the all England teaching in bilingual teaching. Second, read on, because the teachers in the teaching process of grammar and pronunciation is no more clear and strict requirements, high school learn English learning ability is low, pronunciation with the Chinese habit, pronunciation is not accurate, and also use Chinese grammar on the usage habits, will form a "Chinese English". Third, writing, English spelling, college students of English, can the overall English ability has been the national unified examination, inspection, but in all the critical leakage problems in English teaching is the student English vocabulary is not enough, for a variety of meanings of same kind of English words understanding is not comprehensive, and therefore can only realize that a little knowledge of bilingual teaching, can't let college students' English teaching and bilingual teaching.

The Problems and Causes of Current Bilingual Teaching. Bilingual teaching by investigating can learn, accept students in their English learning ability than traditional culture in English teaching of students, many students in English listening, speaking, reading and writing are top notch., mainly terrier redstone language in traditional English teaching mode, in the form of application will improve academic performance as the main purpose of teaching, lead to the student's English is very good, but the actual application of the integrated use of ability is very weak. It application in the teaching of "high score low energy", the traditional university is used to teach, the content of the study is not coherent, there is no correlation, the content of the student cannot achieve unity with the theme of the students. At present, the low quality of college English teaching, bilingual teaching is a direct impact on the normal conduct of key elements of the ability of the English and bilingual course content disconnect. Therefore, part of the students' English learning thought is still stay in the traditional English learning atmosphere, in the depths of his thought is not very agree with bilingual teaching ideas, and is limited by professional English ability, the whole English teaching, students are hard to understand, in the long run, lead to the students' interest in English study is missing, application of teaching and learning contradiction in the teaching, combined with the lack of students' ability in professional college English teaching, bilingual teaching impeded, not easy to form a good cohesion between tacit understanding.

\section{Improve the Thinking of College English Teaching}

We will Further Deepen the Reform of College English Teaching and Try to Make the Teaching Model based on the Content of Subject Matter. The teaching reform of university English can try to transform the simple language learning into content learning by using the teaching mode of subject content. Namely in the higher stages of college English teaching, the 
language learning to learning content, the carrier, in using the language of content (such as culture, professional class knowledge popularization and introduction, etc.) of the study, students in imperceptible in improving language skills. Moreover, students' interests can be improved appropriately. Students should be able to improve their language with knowledge learning as soon as possible after mastering certain rules and vocabulary and reaching a certain level. "Content based" teaching pattern originated in the west, as early as in A.D. 389, Augustine (st. Augustine) is put forward in the language teaching in a meaningful content as the center point of view. Since the 1960s, the "content relying" teaching has received more and more attention and support from teachers and researchers. Brinton, etc (1989) argue that depending on the type of teaching is to teach discipline knowledge and language skills at the same time, combining language teaching students to learn discipline knowledge, student learning is focused on by foreign language acquisition of knowledge, at the same time, through the study of the content to raise the level of language. Bilingual teaching can be regarded as a reality check for college English teaching, and can also be regarded as an in-depth study of English teaching in college. The teaching method of content relying mode can improve the students' interest, improve the students' English level, and the teaching method can also be used in bilingual teaching.

In college English teaching, cultivate the students' English ility. English thinking refers to the ability to understand, judge, and express in English without any interference in the native language or native language. Many students feel after college, is not making much progress in English learning, seems to be the bottleneck, and that students can not use English thinking about: (1) the east-west differences in thinking and expression. If the English mind is more objective, the expression is more subject to the subject. The Chinese thinking is more subjective and has more people in the expression. Chinese people are sensitive and intuitive; Westerners are rational and logical. (2) in English learning and application, it is very important to know whether to be able to speak English fluently in English. In high school, the students master the basic English grammar, a certain amount of vocabulary, if you don't have English thinking ability, students in college English learning may still stay in the increase of vocabulary, reading ability enhancement, examination skills to improve the level. (3) many students feel that it is difficult to improve their ability to hear, and they feel inadequate in oral communication. One important reason is that students are used to the translation of english-chinese and chinese-english translation in their minds. In this way, students still need to look for words that match the Chinese language. In addition, the student's composition is easy to get Chinglish, also because the student is used in the mind to use the Chinese idea, then translate it into English.

Let the Students Contact English in all Aspects. he main way for Chinese students to acquire knowledge is the teaching material, which is usually processed and is different from the actual application of the language. The choice of students' learning content can be varied. College students are holding a college English textbook and a set of workbooks, which can be done in this way. But it is not enough to improve your English. In recent years, college English teaching reform has two changes: (1) strengthen the cultivation of listening and speaking skills, use of television, cd-rom, Internet, films, such as a variety of ways, many kinds of ways to let the students contact English; (2) adopting the modern information technology, such as multimedia and Internet, to implement the new teaching mode. Information society, the latest and immediate information can be readily available. The student's learning content should not be confined to the textbook. Contemporary society, the network, the media can bring during a live broadcast, television, magazines, the latest foreign mainstream media professional journals also relatively easy to get, college English teachers can try to put these as supplementary material of listening, reading, use on a regular basis. Students should be encouraged to use English for information to absorb the information they are interested in. In addition, we will extend the classroom by giving lectures on English, English corner, English reading, etc. All-round contact English gives students learn English environment, is the language learning into a way of learning content, can be in imperceptible in cultivating the students' English thinking ability, improve students' English skills. 
In the teaching of college English, it is early to integrate the knowledge of the student's related discipline Because of professional course teaching material of professional and technical, make early into the bilingual teaching of students' understanding of the term, the completion of the understanding and practice of the teaching material content, etc have certain difficulties. In order to accommodate the students, the teachers have to spend more time on the language, and the bilingual specialized courses are finally become specialized in foreign language teaching. This is a common problem at present. In order to guarantee the college English teaching and the smooth transition of bilingual teaching of specialized course, we believe that in college English teaching, the best early in the teaching material content, supplementary materials and guidance books into the students in the professional related discipline knowledge, and can be set up relevant elective courses, to eliminate obstacles of bilingual curriculum. Of course, this has also made new demands on the knowledge breadth of our former English teachers.

\section{Suggestions for Improving Bilingual Education}

The Application-specific Organization is Responsible for the Link. ow in order to better promote the college English teaching and the cohesion between bilingual teaching work, in the short term to better improve the bilingual teaching effect and quality, we have the necessary application special agencies to manage college English teaching and bilingual teaching, improve the cohesion between the two, specialized for the actual situation of the school make rational plans for the development of the English teaching and bilingual teaching, it can better know the university English teaching and bilingual teaching according to certain plans and steps in the work. The main task of this department is to be able to better handle the teaching links and exchanges between the two, regular teachers together in both the teaching research, such not only can effectively improve the efficiency of the connection between the two, will also be able to know a targeted to college English teaching to the development of bilingual teaching.

5.2 We will improve the training of bilingual teachers in specialized courses. For now university bilingual teacher, they not only need to master professional knowledge, also need to have the good knowledge of English teaching and the teaching ability. In today's English bilingual teaching, bilingual teachers in general is no problem, but in college English teaching, English teachers in general are all professional English teachers, their professional knowledge of the subject is not a lot, that is not conducive to undertake to the student during the period of teachers in the teaching of the penetration of professional knowledge, help bilingual teaching lays the foundation, so now the practice of our country is the most main is some training in college English teaching, help to update the knowledge structure of English teachers, to improve English teachers' understanding of the subject professional knowledge, so in the process of teaching English teachers can better the penetration of professional knowledge to the students.

Make Sure Bilingualism Teaching has enough Time. $n$ recent years, with the reform of Chinese colleges and universities, all courses have been reduced in credits and hours. But bilingual classes for students and teachers, not only to achieve the purpose of the professional teaching requirements, and will involve some language learning needs, the classroom and after-school need than other specialized courses for many time. Thus, the problem of time deficiency becomes a factor in the effect of bilingual teaching. The questionnaire also reflects students' belief that a lack of learning time is also a barrier to learning bilingual courses. The consequences are often, or teacher hurried through teaching content within the period, the students don't have enough time to review after class to understand, learn a little knowledge; Either the teacher chooses to teach a few chapters, the study completes, the student is not tired, but does not reach bilingual teaching the professional teaching objective request. For this, it is recommended that during the course of the teaching plan, the content portion of the bilingual course should be increased, and the credit and the class should be added appropriately. 


\section{Conclusion}

To sum up, in order to better improve the purpose of the bilingual teaching of university now, to realize the improvement of English comprehensive ability and the win-win situation of subject professional knowledge learning, we must improve the cohesion of college English teaching and bilingual teaching. This paper mainly discusses this aspect, and hopes to help the English teaching and bilingual teaching in universities.

\section{References}

[1].E.Zhou,N.Q.Ding. The link between English teaching and bilingual teaching in college: the present situation and the thinking[J].Foreign Language World,2012 (36) : 11-12.

[2].T.Wang. The link between the teaching and the bilingual teaching in the university[J] . Electronic manufacture, 2014 (23) : 15-16.

[3].D.Y.Liu.The cohesion of English teaching and bilingual teaching in college [J] .Northwest medicine education ,2011 (06) : 15-16.

[4].B.H.Wu,M.R.Chen.To realize the strategy of the college English teaching and bilingual teaching[J].Young writers, 2013, 11 (27) : 241-242.

[5].X.E.Cui.The link between the teaching and the bilingual teaching in the university is the problem[J].Electronic manufacture, 2014, (13) : 121-122.

[6].P.J.Liu.The bridging problem of college English teaching and bilingualism is superficial[J].A naked, 2014, (24): 91. 